\title{
TURISMO E IDENTIDAD EN SAN MIGUEL DE ALLENDE, MÉXICO
}

\author{
Luis Ángel Soto de Anda \\ Universidad Autónoma del Estado de México \\ https://orcid.org/0000-0002-2639-5464 \\ Graciela Cruz Jiménez. \\ Universidad Autónoma del Estado de México \\ https://orcid.org/0000-0003-0608-4682 \\ Elva Esther Vargas Martínez \\ Universidad Autónoma del Estado de México \\ https://orcid.org/0000-0003-2657-2691
}

\section{RESUMEN}

El artículo aborda a la identidad como categoría de análisis desde una perspectiva turística en San Miguel de Allende (SMA). La investigación tuvo como soporte una metodología cualitativa sustentada en el método histórico y etnográfico. Entre los principales hallazgos figura que el turismo ha posicionado las manifestaciones culturales de los sanmiguelenses en las preferencias del público nacional e internacional, afianzando una serie de referentes identitarios que vinculan a la población local con su espacio físico y social, además de promover un turismo amigable y receptivo con visitantes de diferentes partes del mundo. Se concluye que los sectores público, social y privado, deben emprender un trabajo colaborativo para rescatar y afianzar la identidad.

Palabras clave: Turismo; identidad; San Miguel de Allende; México.

\section{Tourism and identity in San Miguel de Allende, México}

Fecha de recepción: 23 de mayo de 2018

Fecha de aceptación: 20 de diciembre de 2018

Instituto Literario \# 100. Col. Centro. C.P. 50000. TOLUCA (México). E-mail: angel.s.k@hotmail.com, gracicj@hotmail.com,elvacolegio@gmail.com 


\begin{abstract}
The article research the identity as an analysis category from a tourist perspective in San Miguel de Allende (SMA). The investigation had as support a qualitative methodology based on the historic and ethnographic method. Among the principal findings, tourism has been preferred in national and international public's as a cultural manifestation of the native population of San Miguel de Allende, supporting a series of identity references that link local population with their physical and social environment, besides that promotes a friendly and receptive tourism with visitors of different parts of the world. It is concluded that the public, social and private sectors must start a collaborative effort to rescue and support the identity.
\end{abstract}

Keywords: Tourism; identity; San Miguel de Allende; México.

\title{
1. INTRODUCCIÓN
}

En el contexto internacional las innovaciones tecnológicas han contribuido a modificar la forma de promocionar los destinos turísticos, derivado de nuevos y más altos estándares de productividad (Brenes, 2006). A causa de ello, la tecnificación e industrialización de los procesos económicos ha llevado a transformar estructuras ideológicas y organizativas que repercuten directamente en grupos e individuos. Además, la apertura de mercados ha derribado fronteras geográficas y simbólicas, dándole al ser humano la oportunidad de conocer y experimentar espacios ajenos a su contexto en tiempo real. En este sentido, López y Marín aseguran que "Si las nuevas formas de turismo refieren a insólitas modalidades de consumo y a nuevas experiencias del turista, la trascendencia que viven los locales se relaciona con los procesos de apropiación territorial y la forma en que son representados" (2010:233).

Conviene subrayar que la demanda turística posee un vínculo estrecho con la globalización; por tanto, espacios cargados de sentido y significación refieren procesos permanentes en que el ser humano realiza reflexiones sobre su entorno para comprenderlo y transformarlo (Mac Gregor, 2005). Asimismo, Ocampo (2008) refiere que el sujeto deja de ser objeto cuando alcanza un grado de conciencia que lo sitúa dentro de una posición económica y social; situación que reconfigura atributos de las culturas, ya que éstas se adaptan constantemente a modelos hegemónicos que promueven patrones en el consumo de marcas, productos, incluso destinos turísticos.

Conviene subrayar que destinos turísticos privilegiados con recursos patrimoniales (culturales, históricos, naturales) enfrentan de manera gradual procesos complejos de intervención social al entrar en contacto con otros entes (individuos, grupos, instituciones, organizaciones, culturas, entre otras); en ellos, el sector público impulsa la generación de discursos y prácticas para la resolución de conflictos, problemas sociales y necesidades locales. En este sentido, la iniciativa pública y privada en sus diferentes niveles promueve el intercambio de información y bagaje cultural entre locales y foráneos, alterando realidades que reconfiguran la identidad, no sólo de la población local, sino también de los visitantes. 
En opinión de Sandoval, las sociedades participan en procesos de interconexión donde utilizan diferentes estrategias, reglas y recursos para la satisfacción de intereses propios (individuales y colectivos) dentro de espacios determinados (2003:49). Ante tal argumento, se entiende que las sociedades se encuentran en un dilema latente que exige modernizar o excluir las economías locales, en otras palabras, la integridad de los grupos sociales se ve amenazada por un proceso invasivo que vulnera aquellos sectores que han luchado por conservar su cultura, y por mantener los principios que les han dado identidad con el paso de los años.

Habría que plantear también que el ser humano genera experiencia y conocimiento a partir de la interacción con su entorno físico y social, con lo cual enriquece de manera continua su bagaje histórico-cultural, moldeando la percepción que tiene de sí mismo y del otro. Por tanto, construyen su identidad como individuo y como parte de un colectivo. En palabras de Giménez:

La globalización ha tenido un efecto pluralizador sobre las identidades, produciendo una variedad de posibilidades y de nuevas posiciones de identificación. En consecuencia, las identidades se han vuelto más "posicionales", más políticas, más populares y diversas, aunque también menos fijas y menos unificadas. Pero, sobre todo, han dejado de ser transhistóricas (2016: 80).

Ante ello es importante reconocer que el ser humano posee mecanismos innatos de defensa (conciencia) que le permiten comparar y resguardar aquellas manifestaciones útiles o con las que tiene algún grado de afinidad, teniendo en cuenta que la identidad integra un cúmulo de elementos que responden a la necesidad de diferenciarse de otros mediante la asignación de etiquetas sociales que reconocen diferencias geográficas, culturales, históricas, incluso ideológicas.

Empleando las palabras de Moragues (2006), el turismo despierta curiosidad por descubrir nuevos espacios, así como la interacción con otros grupos, ante la evolución de motivaciones y comportamientos. En virtud de dicha inquietud, la coexistencia y fluctuación de atributos culturales dentro de un mismo destino promueve el intercambio y/o transformación de principios identitarios tanto de la población local como de los turistas; en otras palabras, la confrontación de elementos genera una reacción que induce al ser humano a comparar lo propio con lo ajeno, modificando la percepción que tiene de sí mismo y de aquello que lo rodea. A juicio de Laca, Mejía y Yañez:

Sociológicamente, la modernidad ha supuesto el paso de una sociedad de adscripción, donde los individuos heredaban la práctica totalidad de las características de su identidad social, a una sociedad del logro donde los sujetos han de ir construyendo, en contextos de gran movilidad, identidades que requieren ser renovadas periódicamente (2010:41).

En síntesis, la identidad conlleva a descifrar elementos correlacionados que guardan proximidad con la historia y con el bagaje heredado; por tanto, conlleva a reconocer en su totalidad la complejidad de la cultura en todas sus representaciones, lo cual implica que la identidad está en un proceso metamórfico de creación y de recreación constantes a partir de la acción definida como "socialización". Fernández afirma que "hoy en día ni el individuo ni la sociedad tienen un núcleo esencial e inmutable que otorgue a ese ser una identidad fija de por vida" (2014:10). 
Con base en lo anterior, es relevante subrayar que, como disciplina, el turismo ha enfrentado una serie de retos al incorporar en sus líneas investigación temas sobre cultura e identidad; en este desafío, los turismólogos se han apoyado de disciplinas como la antropología, la sociología y la psicología para consolidar un extenso corpus bibliográfico que sustenta, desde enfoques multidisciplinarios, categorías complejas y dinámicas como las aquí discutidas.

Si bien, el discurso teórico-metodológico ha debido replantearse una y otra vez dada la naturaleza del objeto de estudio, la presente colaboración discute y abona al análisis del trinomio "turismo, identidad y cultura". Asimismo, se exponen los resultados de la investigación "San Miguel de Allende, México. Un análisis de la identidad desde los estudios turísticos".

San Miguel de Allende (SMA) es un destino turístico que resguarda un legado histórico y patrimonial que lo ha hecho acreedor a reconocimientos nacionales e internacionales: 1) "Pueblo Mágico" en 2002 por la Secretaría de Turismo de México (Armenta, 2014) 2) "Patrimonio Cultural de la Humanidad" en 2008 por la Organización de las Naciones Unidas para la Educación, la Ciencia y la Cultura (UNESCO, 2008) 3) "Ciudad número 1 en México, América Central y del Sur" en 2016 por la revista Condé Nast Traveler (H. Ayuntamiento de Guanajuato, 2016) y, 4) "Mejor ciudad del mundo" en 2017 por esa misma publicación (Milenio Digital, 2017).

Derivado de estos premios y condecoraciones, SMA se ha popularizado a nivel estatal, nacional e internacional, consolidando de esta manera una imagen turística que difunde sus bienes culturales, así como los referentes identitarios de la población nativa, de los residentes y de personas que se consideran sanmiguelenses por convicción (nacionales y extranjeros).

El destino reviste características particulares que lo hacen propicio para el análisis de la identidad, pues su interacción con visitantes y turistas ha propiciado que las personas originarias de SMA redescubran día con día atributos de su identidad (individual y colectiva), permitiendo la conservación, adhesión, fusión o eliminación de particularidades culturales que repercuten sobre la identidad de la comunidad anfitriona (población local), conformando a su vez una sociedad multicultural donde converge un sinnúmero de identidades que luchan por prevalecer dentro de un mismo contexto.

A partir de los elementos expuestos, la presente colaboración pretende mostrar cómo los sanmiguelenses han fragmentado su identidad y reconfigurado su sentido de pertenencia a partir de la actividad turística. En primer término, el documento presenta el marco teóricometodológico y las categorías de análisis que apoyaron la investigación; expone los métodos, técnicas, herramientas y estrategias correspondientes al trabajo de campo. En el segundo apartado describe el universo de estudio a partir de un breviario histórico-etnográfico que muestra los cambios socioculturales que ha experimentado SMA con el tiempo. La tercera sección contiene los resultados de la investigación, seguidos del análisis y la confrontación de la realidad con los supuestos teóricos que dieron soporte a la investigación. En el último apartado se exponen las principales conclusiones derivadas del estudio.

\section{MARCO TEÓRICO-METODOLÓGICO}

Este apartado contiene el soporte teórico que sirvió de base para la selección de categorías, subcategorías e indicadores del objeto de estudio; también la construcción metodológica que incluyó el diseño de instrumentos de investigación. Presenta además la 
aproximación empírica de la cabecera municipal de San Miguel de Allende, Guanajuato desde mediados de 2016 hasta finales de 2018.

A partir de la consulta de literatura especializada se reconstruyó el fenómeno de estudio tomando en cuenta el análisis del trinomio: identidad, turismo y cultura; las dos primeras categorías centran el objeto de estudio mientras que la cultura fungió como categoría alterna para para la detección de referentes identitarios (elementos culturales propios de un grupo) y bienes culturales propios de SMA (patrimonio cultural material e inmaterial).

La cultura como categoría nodal entre el turismo y la identidad se entiende como un mecanismo de distinción entre grupos e individuos; es decir, refiere un conjunto ordenado de atributos que moldean la vida social del hombre en distintas dimensiones (económica, política, religiosa, social, etc.). Esto quiere decir que no existe sujeto sin cultura, ni cultura sin sujeto, aludiendo que el ser humano es un ser cultural por naturaleza que reinventa e interioriza las formas objetivas (cultura material) y subjetivas (esquemas cognitivos) que integran a la cultura (Giménez, 2005).

En este marco, el turismo se entiende no solo como una actividad económica, sino también como un hecho social vinculado al aprovechamiento y/o explotación patrimonial para la obtención de beneficios económicos, de telecomunicaciones y servicios (Leite y Graburn, 2009). Asimismo, el turismo como fenómeno social preserva, reafirma o amenaza las particularidades de un destino y con ello los referentes que dan identidad a los integrantes de un grupo social (André, 2011).

El marco teórico que dio soporte a la selección de subcategorías se integró mediante la consulta de material especializado en el área de ciencias sociales y humanidades, particularmente del ámbito antropológico y sociológico. Para el caso de la identidad se retomaron los planteamientos de Melucci, 1997; Larraín, 2001; y Giménez, 2017, quienes coinciden en que ésta se compone a partir de 1) Memoria colectiva: Legado histórico que han construido las sociedades con el paso del tiempo; 2) Sentido de pertenencia: Conjunto de manifestaciones socioculturales que utiliza el hombre para crear lazos de afinidad con el espacio geográfico y los grupos sociales que residen en él; y 3) Reconocimiento social: Valoración colectiva mediante la comparación de rasgos que definen o caracterizan al ser humano. Estas tres fueron retomadas como subcategorías.

Dado que la investigación se desarrolló desde la perspectiva turística, la propuesta metodológica integró al turismo y a la cultura como categorías vinculantes al análisis de la identidad; en tal sentido, fue recopilada información del sector público (Secretaría municipal de Turismo); social (gente nativa del municipio, personas que llevan más de cinco años residiendo en SMA, así como visitantes y turistas que arriban al destino) y, privado (empresarios nacionales y extranjeros dedicados a la hotelería, restaurantería y a la venta de artículos de arte). El propósito fue identificar cómo han atendido el rescate del patrimonio material e inmaterial, vislumbrando los referentes identitarios y los bienes culturales que conforman las estructuras de la identidad en San Miguel de Allende. 


\section{Figura 1 \\ DISEÑO METODOLÓGICO PARA EL ESTUDIO DE LA IDENTIDAD, CULTURA Y TURISMO}

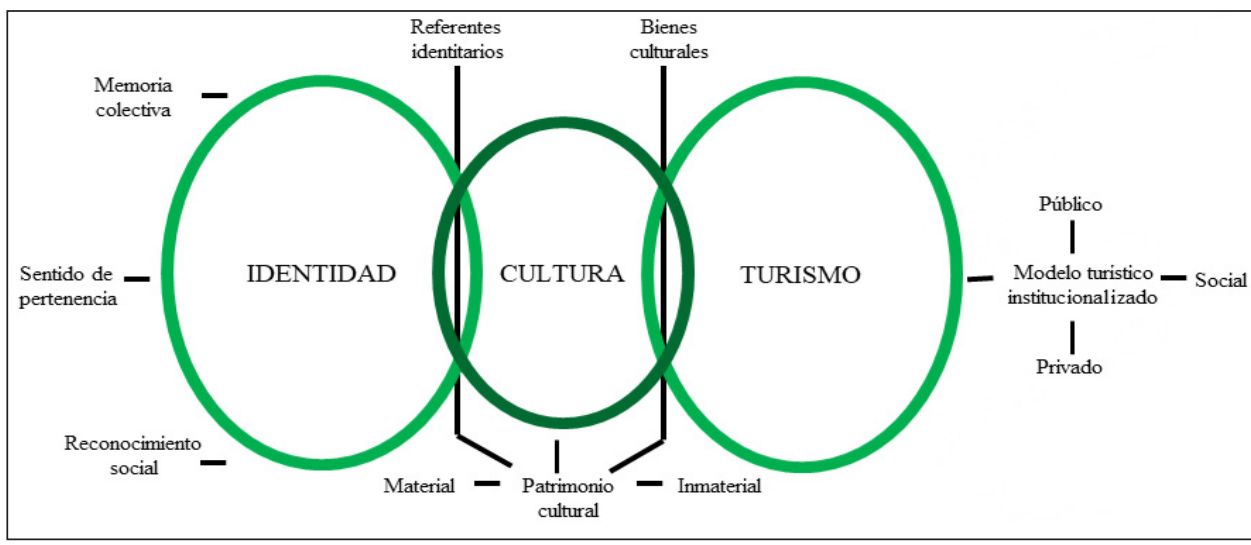

Fuente: Elaboración propia con base en revisión documental.

Una vez definidas las categorías de análisis del trinomio (identidad, turismo y cultura) se retomaron de la literatura especializada como subcategorías: la memoria colectiva, el sentido de pertenencia y el reconocimiento social (Melucci, 1997; Larraín, 2001; Giménez, 2017). Aunado a ello y como aportación científica se proponen dos subcategorías: patrimonio cultural material e inmaterial y modelo turístico institucionalizado. Todas ellas se incluyen en la Tabla 1 donde además se enlistan los indicadores que permiten descifrar y entender la estructura de las identidades desde los estudios turísticos:

Para responder al reto empírico que representaba el estudio de San Miguel de Allende, fue retomado el método etnográfico, partiendo de la esquematización planteada por Angrosino, (2007), para quien la etnografía es un método de campo personalizado en que cada investigador hace énfasis en los factores que considera tienen relación directa con el fenómeno de estudio; también es multifactorial porque posibilita triangular enfoques cualitativos y cuantitativos para un mismo estudio; es inductivo, pues se remite al análisis de los detalles del entorno físico y social; es dialógico en el sentido de que el investigador da voz a la realidad que viven los sujetos que intervienen dentro de la investigación y, es integral porque se remite a un análisis holístico de los resultados.

Desde un enfoque cualitativo, Sabino (1992) sostiene que las entrevistas y cuestionarios, además de otras técnicas de investigación, facilitan obtener un cúmulo de experiencias empíricas, en este caso sobre la realidad de los sanmiguelenses (sector social) respecto a la construcción de identidades y cómo el turismo influye en su fragmentación y/o transformación. Paralelamente, la investigación retomó información de autoridades del sector público, así como de representantes de empresas turísticas (sector privado), a fin de identificar cómo visualizan la identidad local, así como reconocer algunas iniciativas que han emprendido para conservar o rescatar elementos que han dado identidad a los habitantes de este destino. 


\section{Tabla 1 \\ INDICADORES PARA EL ANÁLISIS DE LA IDENTIDAD}

\begin{tabular}{|c|c|c|}
\hline \multicolumn{3}{|c|}{ IDENTIDAD } \\
\hline Memoria colectiva & Sentido de pertenencia & Reconocimiento social \\
\hline $\begin{array}{l}\text { - Transmisión intergene- } \\
\text { racional de la historia. } \\
\text { - Reconocimiento de la } \\
\text { historia local. } \\
\text { - Significado de los he- } \\
\text { chos históricos. } \\
\text { - Preservación del lega- } \\
\text { do histórico. }\end{array}$ & $\begin{array}{l}\text { - Afinidad con el espacio geo- } \\
\text { gráfico. } \\
\text { - Afinidad con el grupo social. } \\
\text { - Objetivos y metas compartidos } \\
\text { con el grupo. } \\
\text { - Asignación de roles y funcio- } \\
\text { nes al interior. } \\
\text { - Apropiación de los bienes cul- } \\
\text { turales. }\end{array}$ & $\begin{array}{l}\text { - Identificación de rasgos que ca- } \\
\text { racterizan el lugar y la población } \\
\text { local. } \\
\text { - Distinción social. } \\
\text { - Asignación de etiquetas socia- } \\
\text { les. } \\
\text { - Comparación social. }\end{array}$ \\
\hline CULTURA & & TURISMO \\
\hline $\begin{array}{l}\text { Patrimonio cultural } \\
\text { material e inmaterial }\end{array}$ & & $\begin{array}{l}\text { Modelo turístico } \\
\text { institucionalizado }\end{array}$ \\
\hline $\begin{array}{l}\text { - Reconocimiento del } \\
\text { patrimonio cultural. } \\
\text { - Significado de los bie- } \\
\text { nes culturales. } \\
\text { - Implementación del } \\
\text { patrimonio cultural. } \\
\text { - Relevancia social del } \\
\text { bagaje heredado. }\end{array}$ & $\begin{array}{l}\text { Categorías } \\
\text { Subcategorías } \\
\text { Indicadores }\end{array}$ & $\begin{array}{l}\text { - Injerencia de los organismos pú- } \\
\text { blicos, sociales y privados. } \\
\text { - Reconocimiento de los bienes } \\
\text { culturales por parte de las insti- } \\
\text { tuciones sociales. } \\
\text { - Importancia de los bienes cultu- } \\
\text { rales dentro del destino turístico. } \\
\text { - Función de los bienes culturales } \\
\text { para el modelo turístico institu- } \\
\text { cionalizado. } \\
\text { - Medidas de preservación del pa- } \\
\text { trimonio cultural. }\end{array}$ \\
\hline
\end{tabular}

Fuente: Elaboración propia con base en revisión documental.

En primera instancia fue retomado el punto de vista de la población que lleva más de cinco años residiendo en SMA (perfil deseable de la muestra); previamente fueron identificados los elementos que este grupo considera propios de SMA y de su gente; complementariamente, se retomó la opinión de visitantes y/o turistas para conocer los bienes culturales que asocian con el destino, así como los referentes identitarios que, vistos desde fuera, distinguen a los sanmiguelenses (perspectiva emic).

Para ello fueron diseñadas entrevistas semiestructuradas que, de acuerdo con Ortiz (2007), son flexibles en cuanto al orden o formulación de las interrogantes. El diseño de esta herramienta incluyó una prueba piloto con especialistas en metodología de la investigación aplicada al turismo y con la población objetivo, tras lo cual fue afinada. 
De manera complementaria fueron empleados cuestionarios que permitieron profundizar sobre los procesos socioculturales derivados de la actividad turística en San Miguel de Allende. Éstos fueron una adaptación del instrumento de captación de información de Piqueras (1996); la nueva versión tuvo como propósito realizar un acercamiento a las manifestaciones culturales (patrimoniales e identitarias) que distinguen a los sanmiguelenses, así como información relacionada con percepciones individuales y colectivas de SMA.

El cuestionario que desarrolló Piqueras para analizar la identidad valenciana a finales de la década de los 90’s tiene una interpretación sociológica. Del instrumento original, esta investigación retomó información relacionada con: alimentación, tradiciones, costumbres y sentido de pertenencia, que vinculan a la cultura con el estudio de las identidades. Para atender los propósitos de esta investigación, el instrumento incorporó al turismo como categoría de análisis para el estudio de la identidad en el destino y se integró de los siguientes apartados:

1. Atractivos turístico-culturales de San Miguel de Allende: El objetivo fue realizar un inventario de los recursos patrimoniales materiales e inmateriales que reconocen los sanmiguelenses, así como determinar el grado de afinidad que guardan con los elementos que, desde su punto de vista, conforman la identidad local.

2. Sanmiguelenses y su reconstrucción identitaria: Este apartado permitió delimitar las concepciones locales en torno a las características que debe poseer un individuo para ser considerado parte del grupo; asimismo, analizar aquellos aspectos que la población endógena considera caracterizan al destino y a los grupos sociales que residen en él.

3. Turismo y sus repercusiones socioculturales: Su propósito fue verificar las repercusiones socioculturales que los sanmiguelenses identifican en relación a cómo el turismo ha repercutido sobre aspectos vinculados con su cultura, patrimonio e identidad individual y colectiva.

Para la aplicación de cuestionarios y la realización de entrevistas semiestructuradas, la superficie territorial de la cabecera municipal de SMA fue dividida en cuatro cuadrantes (noroeste, suroeste, noreste y sureste), atendiendo a la delimitación del mapa turístico que difunde el consejo turístico de esa ciudad (SEGOB y SECTUR Guanajuato, 2018). Posterior a la identificación de los atractivos turísticos más sobresalientes en cada uno de los cuadrantes, fueron aplicados los instrumentos de manera aleatoria. La Tabla 2 muestra las técnicas de investigación utilizadas con los distintos sectores. 
Tabla 2

TÉCNICAS DE INVESTIGACIÓN APLICADAS POR SECTOR

\begin{tabular}{|c|c|c|c|c|}
\hline Sector & $\begin{array}{c}\text { Población } \\
\text { objetivo }\end{array}$ & Técnica empleada & $\begin{array}{l}\text { Número de } \\
\text { instrumentos } \\
\text { aplicados }\end{array}$ & Información obtenida \\
\hline \multirow{11}{*}{ SOCIAL } & \multirow{9}{*}{$\begin{array}{l}\text { Nativos y } \\
\text { residentes }\end{array}$} & \multirow{3}{*}{$\begin{array}{l}\text { Cuestionarios } \\
\text { (adaptación } \\
\text { del modelo de } \\
\text { Piqueras, 1996) }\end{array}$} & \multirow{3}{*}{96} & $\begin{array}{l}\text { - Reconstrucción del perfil } \\
\text { identitario. }\end{array}$ \\
\hline & & & & $\begin{array}{l}\text { Factores socioculturales de } \\
\text { incidencia en la conformación } \\
\text { identitaria. }\end{array}$ \\
\hline & & & & $\begin{array}{l}\text { Selección de informantes } \\
\text { clave. }\end{array}$ \\
\hline & & \multirow{5}{*}{$\begin{array}{c}\text { Entrevista } \\
\text { semiestructurada }\end{array}$} & \multirow{5}{*}{32} & - Memoria colectiva. \\
\hline & & & & - Sentido de pertenencia. \\
\hline & & & & - Reconocimiento social. \\
\hline & & & & $\begin{array}{l}\text { Afinidad con los atractivos } \\
\text { turístico- culturales. }\end{array}$ \\
\hline & & & & $\begin{array}{l}\text { Selección de personas para } \\
\text { la realización de historias de } \\
\text { vida. }\end{array}$ \\
\hline & & Historias de vida* & 6 & $\begin{array}{l}\text { Confrontación } \\
\text { intergeneracional de los } \\
\text { cambios observados en SMA. }\end{array}$ \\
\hline & \multirow{2}{*}{$\begin{array}{l}\text { Visitantes y } \\
\text { turistas }\end{array}$} & \multirow[t]{2}{*}{ Cuestionario } & \multirow[t]{2}{*}{30} & $\begin{array}{l}\text { Referentes identitarios que } \\
\text { caracterizan a SMA y a sus } \\
\text { habitantes. }\end{array}$ \\
\hline & & & & $\begin{array}{l}\text { - Motivos de selección del } \\
\text { destino turístico. }\end{array}$ \\
\hline \multirow{2}{*}{ PÚBLICO } & \multirow{2}{*}{$\begin{array}{l}\text { Autoridades } \\
\text { locales }\end{array}$} & \multirow{2}{*}{$\begin{array}{c}\text { Entrevista } \\
\text { semiestructurada }\end{array}$} & \multirow{2}{*}{3} & $\begin{array}{l}\text { Promoción y difusión del } \\
\text { patrimonio cultural tangible e } \\
\text { intangible. }\end{array}$ \\
\hline & & & & $\begin{array}{l}\text { - Medidas institucionales para } \\
\text { la preservación del patrimonio } \\
\text { cultural. }\end{array}$ \\
\hline PRIVADO & $\begin{array}{l}\text { Representantes } \\
\text { del gremio } \\
\text { hotelero, } \\
\text { restaurantero y } \\
\text { de comercios }\end{array}$ & $\begin{array}{c}\text { Entrevista } \\
\text { semiestructurada }\end{array}$ & 3 & $\begin{array}{l}\text { - Función que cumplen los } \\
\text { bienes culturales para el } \\
\text { sector público y privado. }\end{array}$ \\
\hline
\end{tabular}

*Tres del género masculino y tres del femenino; entre ellos, un representante de género por cada rango de edad (adolescentes, adultos y adultos mayores)

Fuente: Elaboración propia con base en trabajo de campo. 
En palabras de Arias (2012), la selección de la población corresponde a un muestreo intencional u opinático. A partir de ello y según los propósitos de la investigación, la muestra fue delimitada en 1) habitantes de nacionalidad mexicana; 2) Sujetos con cinco años o más de residencia en SMA, independientemente de su lugar de nacimiento y; 3) Personas mayores de 18 años.

El perfil de la población local correspondió a:

- Número de personas: 96

- Género: $58 \%$ femenino y $42 \%$ masculino.

- Nivel de estudios: $8 \%$ primaria, $15 \%$ secundaria, $35 \%$ preparatoria y $42 \%$ licenciatura.

- Rango de edad: 18 a 35 años 48\%; 36 a 55 años 35\%; 56 años en adelante 17\%.

- Lugar de nacimiento: San Miguel de Allende 68\%; otros municipios de Guanajuato 12\%. Querétaro 13\%, Ciudad de México 5\%, Morelia 1\% y Tamaulipas $1 \%$.

- Ocupación: trabajos relacionados con el turismo 61\% (comerciante, cocinero, mesero, barista, recepcionista, organizador de bodas, fotógrafo, artista plástico, entre otras). No relacionados con el turismo 12\% (amas de casa, empleada doméstica, médico, enfermero), estudiantes $27 \%$.

- Lugar de residencia: Atotonilco 10\%, Aurora 8\%, Centro histórico 43\%, San Rafael 7\%, La Cañada 13\%, Comonfort 5\% y Valle del Maíz $14 \%$.

El perfil de la población foránea correspondió a:

- Número de personas: 30

- Género: $60 \%$ femenino y $40 \%$ masculino.

- Nivel de estudios: preparatoria 20\%, licenciatura 60\%, maestría $20 \%$.

- Rango de edad: 18 a 35 años 73\%; de 36 a 55 años $27 \%$.

- Lugar de procedencia: nacional 53\% (Querétaro, Nuevo León, Estado de México, Jalisco, Ciudad de México) y extranjero 47\% (Estados Unidos, Canadá, Francia, Japón, España, Argentina, entre otros).

El perfil del sector público correspondió a:

- Informantes clave: 3

- Ocupación: cargos públicos relacionados con el área turística.

- Lugar de nacimiento: 100\% sanmiguelenses.

- El perfil del sector privado correspondió a:

- Informantes clave: 3

- Ocupación: hotelero, restaurantero, dueño de una galería de arte.

- Lugar de nacimiento: 2 sanmiguelenses y 1 extranjero.

\section{BREVIARIO HISTÓRICO-ETNOGRÁFICO DE SAN MIGUEL DE ALLENDE}

Se parte de un recuento histórico para apreciar cronológicamente los cambios que ha experimentado este destino que forma parte del Estado de Guanajuato, territorio ubicado en el centro de la República Mexicana. Este apartado muestra además las acciones que han 
emprendido el sector público, social y privado para impulsar un nuevo modelo turístico que se guía a partir de las exigencias del mercado global.

Fuentes oficiales aseguran que se fundó en 1542 bajo el nombre de San Miguel el Grande, pueblo carente de servicios e infraestructura debido a las características orográficas derivadas de su ubicación. Asimismo, su proximidad con el Estado de Zacatecas impulsó el desarrollo de un área geográfica rica en recursos minerales (extracción de plata), lo cual alentó la construcción de caminos y/o carreteras que mantuvieron comunicada a la zona centro de la república mexicana, potencializando el crecimiento demográfico y económico del lugar, características que le permitirían obtener la distinción como ciudad en 1826 (López, 2010).

Para finales del siglo XVIII y principios del XIX, el municipio se convirtió en uno de los centros mercantiles, agrícolas e industriales más importantes de la zona centro de México. Al término de la Segunda Guerra Mundial SMA cobró importancia turística a nivel nacional tras el arribo de soldados estadounidenses, canadienses y de origen europeo que decidieron asentarse en el destino tras jubilarse (Destinos México, 2018).

En los 40’s el destino acaparó la mirada de los amantes de la cultura y el arte, en particular de extranjeros interesados por conocer la historia de una nación mediante diferentes expresiones artísticas. Durante esta década, David Alfaro Siqueiros impartió talleres de pintura y muralismo mexicano en la Escuela de Bellas Artes; los veteranos de guerra fueron los principales asistentes (Herrera, 2018). En la década de los 50’s SMA se convirtió en un destino turístico con reconocimiento nacional e internacional por la arquitectura de varias de sus edificaciones, entre ellas la Parroquia de San Miguel Arcángel, inmueble representativo con estilos que van desde el Barroco hasta el Neogótico (SECTUR, 2018).

En concordancia con lo planteado en la parte introductoria, SMA ha recibido un sinnúmero de reconocimientos nacionales e internacionales, por lo que está posicionado como un destino rico en cultura, historia y recursos naturales; un modelo turístico innovador y de vanguardia que se adapta a las necesidades de un mercado exigente y competitivo. En 2002 este destino obtuvo el nombramiento de "Pueblo Mágico", que otorga la SECTUR a sitios que conservan atributos culturales e históricos de México; en 2008 tal distinción le fue revocada porque la UNESCO la reconoció como ciudad patrimonio cultural de la humanidad y no podía contar con ambos nombramientos. En este sentido, autoridades, empresarios y la sociedad local han tenido que adecuarse a los estándares nacionales e internacionales (SECTUR y UNESCO, respectivamente) que promueven la actividad turística, buscando el rescate y preservación del patrimonio cultural y natural de SMA, no sólo porque acoge los bienes que consolidan la identidad sanmiguelense, sino también porque representa un legado para la humanidad.

Posterior a los referidos nombramientos y a la inversión tanto pública como privada canalizada al municipio, éste ha promovido las modalidades de turismo de negocios y residencial, favoreciendo la construcción de hoteles, unidades habitacionales y centros de retiro para extranjeros, opciones para un sector elitista que posee un alto poder adquisitivo respecto al de los residentes.

La Secretaría de Gobernación y la Secretaría de Turismo del Estado de Guanajuato (2017) dieron a conocer que 62\% de los turistas que arriban en SMA son nacionales (Ciudad de México, Jalisco, Estado de México, Querétaro y Nuevo León); $23 \%$ estatales 
(León, Celaya, Guanajuato, Irapuato y Dolores Hidalgo) y 15\% internacionales (Estados Unidos, Canadá, España, Colombia y Argentina). Asimismo, 43\% practica turismo cultural; $28 \%$ de placer y entretenimiento; $10 \%$ de negocios/trabajo; $6 \%$ de romance/bodas; $5 \%$ gastronómico; $3 \%$ de compras; $2 \%$ religioso y $3 \%$ otro tipo de actividades (turismo estudiantil, de reuniones y deportivo/aventura).

Según estadísticas del Consejo de Turismo de San Miguel de Allende, éste se ha convertido en un concepto turístico altamente rentable para la inversión nacional y extranjera; en 2017 recibió más de 1 millón 430 mil 931 visitantes, 15\% más respecto al año anterior. En tanto, la afluencia turística generó una derrama económica de 6 mil 390 millones 861 mil 948 pesos, lo que significó un aumento de 18\% respecto a 2016 (SECTUR Guanajuato, 2017b).

En tal contexto, el secretario de Turismo del Estado de Guanajuato, Fernando Olivera Rocha (SECTUR Guanajuato, 2017a) asegura que la promoción, difusión y desarrollo de nuevos productos ha reinventado la manera de hacer turismo, lo cual atribuye a que San Miguel de Allende tiene como ventaja que la sociedad, empresa y gobierno han trabajado coordinadamente.

Las autoridades locales están conscientes de los retos que enfrentan desde que SMA fue reconocida como una de las ciudades más importantes de México y del mundo por su riqueza histórica, religiosa, arqueológica, arquitectónica, cultural, así como su oferta turística, sostuvo el presidente de la Asociación de Hoteles de San Miguel de Allende. Ante tal condición, los sectores público, social y privado se han propuesto conservar el legado cultural de la población así como impulsar la economía local, estatal y nacional.

Actualmente San Miguel de Allende es considerado por turistas y visitantes como una ciudad cosmopolita donde interactúan sujetos de diferentes partes del mundo, por lo cual su sociedad es multicultural, ya que en su territorio convergen elementos lingüísticos, gastronómicos y musicales endógenos y exógenos, pues se han conservado, adoptado y adaptado manifestaciones que no necesariamente forman parte de la cultura local. Ante esta situación, el sector público y privado han construido una imagen turística del México tradicional, mediante el rescate de atractivos que aluden a las raíces del pueblo mexicano; creencias, tradiciones, costumbres, mitos, leyendas, conocimientos y arte, entre otros atractivos que conservan el pasado prehispánico, pero sobre todo colonial del destino. Aunado a esto, la propuesta de SMA respalda una oferta turística que rescata la riqueza del lugar y de su gente, apegándolas a estándares de calidad y vanguardia que lo posicionan como un destino ampliamente competitivo a nivel nacional e internacional.

Con base en este panorama es posible apreciar que la focalización turística que han emprendido el sector público y privado ha dejado de lado posibilidades e intereses de los sanmiguelenses, tomando en cuenta que el gobierno y la política turística han encaminado el modelo de desarrollo a la creación de servicios cinco estrellas, así como a la satisfacción de necesidades y exigencias de un mercado globalizado.

\section{APROXIMACIÓN EMPÍRICA AL OBJETO DE ESTUDIO}

La identidad como proceso inacabado adquiere diferentes connotaciones estructurales de acuerdo con necesidades y/o exigencias sociales que moldea un contexto delimitado 
sincrónica y diacrónicamente. La Figura 2 expone una serie de elementos que, según los sanmiguelenses entrevistados, conforman su identidad.

La figura 2 fue diseñada con base en los resultados del cuestionario aplicado a 96 sujetos. Una vez vaciada la información sobre una matriz de Excel, se contabilizó la frecuencia de las respuestas, integrándolas en 24 categorías que se enlistan del 1 al 24, donde 1 representa la respuesta más mencionada y 24 la menos mencionada. La figura se interpreta del centro hacia la periferia; los números se desarrollan de manera secuencial, donde 1 representa mayor influencia para la conformación de la identidad de los sanmiguelenses y 24 , menor grado de injerencia.

\section{Figura 2}

\section{ELEMENTOS QUE INTEGRAN A LA IDENTIDAD DE SAN MIGUEL DE ALLENDE}
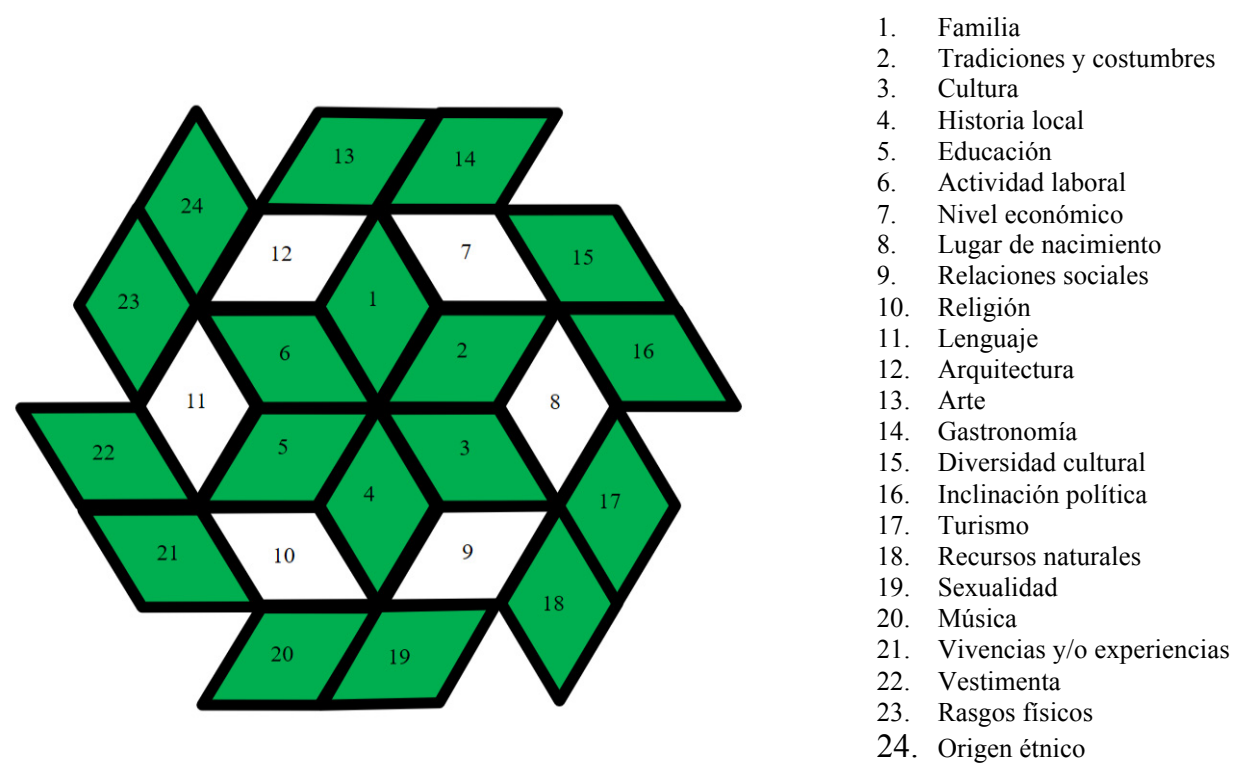

Fuente: Elaboración propia con base en los resultados de la encuesta.

El análisis de estas dimensiones apoyado por el sustento teórico-metodológico, permitió reconstruir la identidad de los habitantes de SMA desde una introspección local; es decir, reconstruir la identidad a partir de una visión que retoma la opinión de la población local, así como de quienes llevan viviendo en el destino más de cinco años. Como parte de la aproximación empírica, el Gráfico 1 enlista una serie de factores socioculturales que inciden sobre la reconfiguración identitaria de esta población.

Este gráfico se diseñó con la información vertida en los 96 cuestionarios. Se solicitó a la población local identificar como mínimo dos aspectos que consideraban influían en la conformación de su identidad; de ello se obtuvieron 256 respuestas que fueron agrupadas 


\section{Gráfico 1 \\ FACTORES SOCIOCULTURALES QUE INTERVIENEN EN LA RECONFIGU- RACIÓN IDENTITARIA DE SMA}

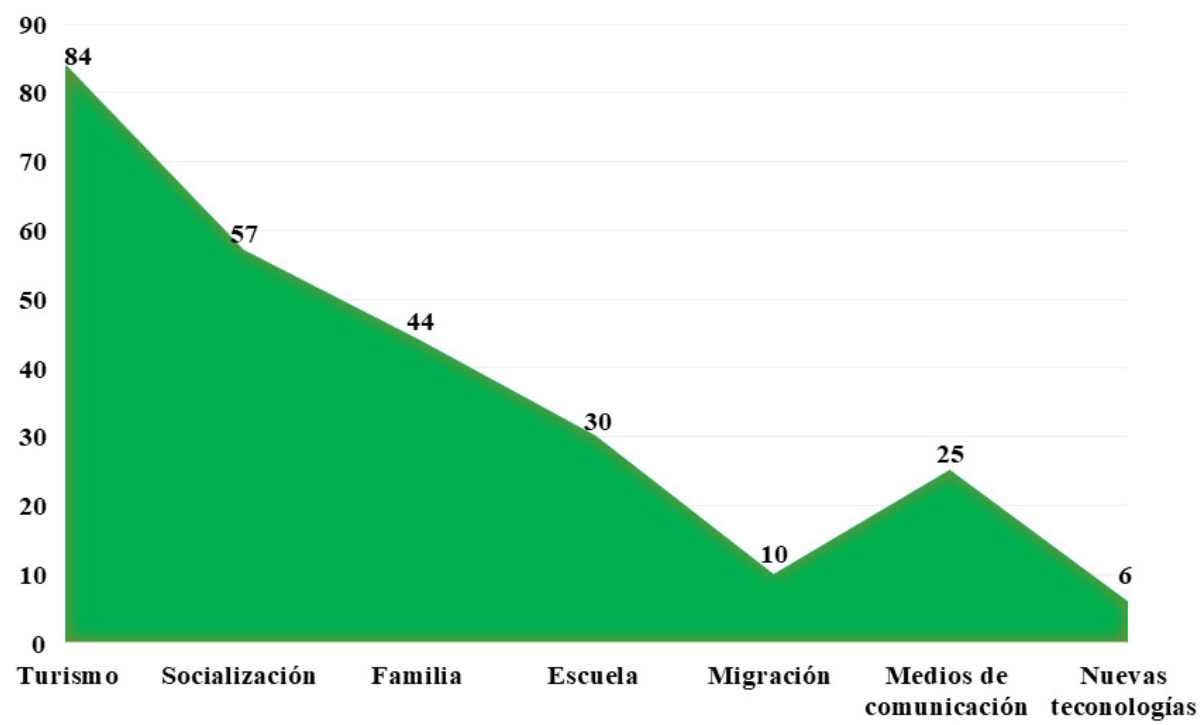

Fuente: Elaboración propia con base en los resultados de la encuesta.

en siete categorías (turismo, socialización, familia, escuela, migración, medios de comunicación y nuevas tecnologías).

Del análisis de esta figura, destaca que el turismo ha sido el principal factor de incidencia sobre la reconfiguración identitaria de los habitantes de SMA; en tal sentido, vale la pena aclarar que esta actividad como fenómeno social, se vincula estrechamente con la globalización, por lo que se desencadena una serie de transformaciones que articulan a esta categoría con aspectos paralelos como la migración y la aculturación, los cuales se refieren al contacto entre sujetos de contextos geográficos y socioculturales distintos, promoviendo el intercambio de elementos culturales y con ello la reconfiguración de las identidades que acogen a turistas y visitantes dentro de los destinos turísticos.

Por otro lado, la familia promueve la enseñanza y reproducción de pautas socialmente establecidas a partir del conocimiento intergeneracional que se transmite mediante relaciones de consanguinidad, parentesco, amistad, entre otras. De acuerdo a lo planteado, es en el núcleo familiar donde se gesta el primer acercamiento con concepciones culturales, éticas, morales, políticas, religiosas, sexuales, entre otras. En particular, los sanmiguelenses están conscientes del relevante peso que tiene esta institución y donde cada miembro del grupo posee una función que se asocia a la formación del "ciudadano". Por su parte, las instituciones educativas promueven la enseñanza a partir de la estandarización de conocimientos que se adecuan a edades y contextos. En otras palabras, el sistema escolarizado 
condiciona el conocimiento de una región mediante planes de estudio que promueve el rescate de la identidad individual y colectiva. Por otro lado, el cumplimento de la normatividad institucional no sólo forma a la sociedad en áreas específicas, sino que también condiciona la cultura y el sentido de pertenencia a partir de pautas socialmente aprobadas. Si bien ambas instituciones cumplen la función de formar a los individuos dentro de un contexto, en el plano familiar recae el compromiso de delegar y difundir los conocimientos heredados, permitiendo reforzar el tejido familiar y social de un colectivo que comparte un espacio geográfico y sociocultural especifico.

Otro de los factores que repercute sobre la construcción de las identidades se vinculó al proceso de socialización, haciendo hincapié en el contacto entre turistas y locales. Los sanmiguelenses refieren que, aunque existe un arraigo de pautas culturales, la constante interacción con personas ajenas al contexto ha llevado a redimensionar sus concepciones socioculturales para adecuarlas y/o "sofisticarlas" a las demandas de un sector élite (extranjeros). De manera complementaria destaca que la migración ha promovido el flujo de individuos y con ello el asentamiento de personas foráneas por periodos prolongados o cortos, quienes regresan a su lugar de origen con una cosmovisión distinta, mientras que la población local se ha tenido que adaptar a turistas y visitantes sin perder atributos de su identidad y de su cultura; es decir, recuperar, resguardar y difundir el legado de nativos y locales.

Por su parte los medios de comunicación fueron reconocidos por la población de 14 a 35 años como instrumentos masivos para la recepción de información; aluden que la televisión y las redes sociales son un factor que influencia la reconfiguración de las percepciones sobre una persona, una comunidad, o en este caso, de un destino turístico. De manera semejante, la implementación de nuevas tecnologías ha transformado la realización de actividades como la ganadería y la agricultura, así como técnicas vinculadas a procesos de producción artesanal y de alimentos (Testimonios del sector de 56 años en adelante). Otro de los testimonios hizo alusión al cambio de actividades económicas y laborales, refiriendo que las personas dejaron la agricultura y la ganadería para insertarse como prestadores de servicios o como comerciantes en la industria turística

Asimismo, dadas las exigencias del turismo se han insertado nuevos establecimientos comerciales: "Starbucks", "The Italian Coffee Company" y "Tiendas Oxxo" son solo algunos de ellos, afectando directamente a los sanmiguelenses que viven de la venta de productos similares. Según el testimonio de un habitante local: "prefieren comprar un café de más de 100 pesos con productos importados, a un café de olla con productos locales de la señora de la esquina" (López, L., entrevista, 28/12/2017). Derivado del análisis de las historias de vida, los sanmiguelenses reconocen que con el paso del tiempo el municipio ha presentado cambios paulatinos en cuanto a crecimiento demográfico, creación de nuevos pueblos, colonias, unidades habitacionales y residenciales, así como la turistificación del territorio.

Una vez que fueron planteados los elementos que estructuran a la identidad y los factores socioculturales que inciden en la reconfiguración de esta categoría, en el siguiente apartado son analizados los resultados, a partir de la articulación del trinomio de estudio; se interpreta además el papel que ha jugado el sector público, social y privado para la conservación del patrimonio cultural material e inmaterial de SMA. 


\section{ANÁLISIS Y DISCUSIÓN DE RESULTADOS}

El ser humano construye su bagaje histórico mediante las experiencias que adquiere en su entorno físico y social. En el caso particular de San Miguel de Allende, sus habitantes consolidan su identidad colectiva a partir del rescate de elementos caracterológicos de su cultura y de su historia; el turismo es uno de los factores que ha impulsado la difusión de un legado socialmente construido y turísticamente consolidado.

Como contexto de los elementos que integran la identidad sanmiguelense (percepción de la población local), se tiene que los núcleos familiares se han convertido en el elemento central para la cesión del legado que caracteriza a SMA y que define a su gente, lo que representa un proceso endoculturativo donde la tradición oral ha facilitado la difusión del conocimiento local entre los sanmiguelenses y el público en general; en este sentido, las generaciones de mayor edad se han encargado de transmitir un bagaje conceptual a los más jóvenes, siendo éstos quienes han asumido el reto de conservar aspectos representativos de su historia y de su cultura; ejemplo de ello son los hechos de la independencia de México acaecidos en territorio sanmiguelense, así como las fiestas patronales que integran el calendario litúrgico. De manera paralela, las instituciones educativas en sus diferentes niveles, abordan temas históricos y de tradición local que fomentan desde edades tempranas el reconocimiento de las raíces sanmiguelenses.

Complementariamente, los museos públicos y privados se han convertido con sus exposiciones temporales y permanentes, en espacios intergeneracionales donde el conocimiento fluye entre los interesados por conocer más sobre lo que representa ser mexicano y sanmiguelense. Entre los principales espacios destacan: el "Museo Histórico Casa de Allende", la "Casa del Mayorazgo de la Canal", el "Museo la Esquina", "El museo de la Catrina", "Museo la Otra Cara de México" y el "Centro cultural de arte y diseño La Aurora", los cuales promocionan el eslogan "San Miguel de Allende: El Corazón de México". Éstos resguardan el legado cultural de este pueblo que ha luchado por reforzar una mexicanidad mediante la difusión de su historia, de su arte y de su tradición.

En contraparte, museos como "La esquina" (acervo de juguetes rústicos/artesanales de México) y "La catrina” (exhibición de tradiciones, usos y costumbres de México relacionados al día de muertos) promueven la identidad nacional antes que la local, desfavoreciendo la difusión y el arraigo de elementos endógenos. En la misma sintonía, SMA ha canalizado esfuerzos a consolidar una imagen del México tradicional mediante su arquitectura, festividades, costumbres, alimentos y experiencias con la población local.

En otro punto de ideas, algunos de los entrevistados afirman que han adquirido por iniciativa propia el conocimiento sobre la historia del lugar; libros y páginas de internet despejan sus dudas sobre determinados temas. No obstante, la memoria colectiva de la población sanmiguelense se ha ido mermando a causa de la desinformación, la falta de interés y a la reconfiguración de las relaciones cara a cara. En palabras de una de sus habitantes: "los jóvenes ya no se interesan por conocer como vivíamos, qué comíamos, a qué jugábamos ... hoy solo se la viven pegados al celular y no ven qué hay más allá de sus narices" (García, C., entrevista, 18/06/2017). Ante esta situación es necesario reconocer que la conservación del legado histórico y la exploración interna del "yo" y la "otredad" enriquece las concepciones culturales e identitarias desde lo individual hasta lo colectivo. 
De igual forma, los sanmiguelenses aseguran que la historia local les ha permitido conocer más acerca de quiénes son y de lo que han hecho por SMA tanto los antepasados como las actuales familias. La población originaria del municipio aseguró sentir un apego emocional a los bienes heredados; aunado a esto, los actuales residentes (personas que viven en el municipio desde hace cinco o más años), afirman que los bienes culturales de su actual "hogar" les ha permitido valorar su lugar de procedencia, además de haber creado lazos sociales que los hace sentirse parte de un grupo.

En otro punto de ideas, la afinidad geográfica se relaciona directamente con el territorio y los recursos que posee. Con base en la información recopilada, a un amplio sector de la población (89\%) le gusta vivir en SMA; sus respuestas aluden en orden descendente de importancia a: la historia, tradiciones y costumbres, tranquilidad, seguridad, oferta de servicios, hospitalidad de la gente, diversidad artística, cultural y arquitectónica, clima, incluso el contacto con visitantes y turista. Por su parte, al resto no gusta de vivir en este destino por los siguientes motivos: afluencia excesiva de extranjeros, alto precio en productos y servicios, contaminación, tráfico automovilístico, razones que les generan estrés.

Por otro lado, el $46 \%$ de los testimonios consideran sanmiguelense a quienes no nacieron en el SMA, pero que en la actualidad residen en el destino. Con el $31 \%$, la respuesta "parcialmente" se justificó a partir de los siguientes argumentos: "depende del tiempo que lleve fuera", "ser de un lugar o pertenecer a él no siempre se relaciona con el lugar de nacimiento". El 23\% restante afirmó que no debe considerarse como sanmiguelense porque "no contribuye con el municipio" y "no participa en las festividades".

De manera simultánea, el estudio arrojó que $77 \%$ de la población se considera sanmiguelense, aseguran que el hecho de nacer en San Miguel de Allende los acredita como tales); $19 \%$ se asumen parcialmente como tal y, $4 \%$ no. Comparando la cifra con el perfil de los encuestados, se aprecia que al $68 \%$ de la población nacida en SMA se suma un $9 \%$ de personas que no necesariamente son originarias del lugar, pero que al tener más de cinco años residiendo en el destino los ha llevado a sentir un apego por el lugar y las personas que habitan en su entorno.

Entre las principales razones destaca que los residentes comparten objetivos y metas en común, ya sea por familia, colonia o poblado, haciendo frente al cuidado del espacio que comparten (calles, lugares públicos y casas), así como a la seguridad entre vecinos y turistas. De igual forma, los habitantes se coordinan para la realización festividades, ya sea aportando recursos económicos o fuerza de trabajo para celebraciones lúdicas o tradicionales ante las diferentes comisiones locales. En este tipo de actividades, cada uno de los representantes y/o habitantes asume una función según sus preferencias, habilidades, género y edad.

Los sanmiguelenses testifican que el destino posee atractivos con valor histórico, cultural, arqueológico y natural. La Tabla 3 expone un listado de sitios donde la población clasificó sus bienes culturales en torno a "importancia histórica" y "representatividad turística".

En el cuestionario se solicitó a la población local identificar de manera abierta como máximo tres sitios de importancia histórica y tres de representatividad turística en SMA. 
Las respuestas registradas fueron clasificadas en una matriz de Excel, arrojando un total de 17 opciones apreciables en la Tabla 3.

Respecto al primer aspecto correspondiente a la importancia histórica, la división geográfica del espacio de estudio identificó que los sanmiguelenses guardan una estrecha relación con los bienes culturales del centro puesto que forman parte de un referente identitario de tipo colectivo. Aunado a esto, la investigación mostró que la población desarrolla afinidad con los bienes próximos a su vivienda o al lugar donde realizan sus actividades diarias, asociándolos al sentido de pertenencia, así como a la apropiación de bienes, debido a que desarrollan lazos emocionales o afectivos con el patrimonio local (asociación de vivencias y experiencias con los recursos que resguarda el territorio donde residen.

Para ejemplificar dicho argumento, se retoma el siguiente fragmento de un testimonio:

"Toda mi vida he vivido en San Miguel [...] esta fue casa de mi abuelo [...] me acuerdo cuando nos llevaban a la iglesia todos los domingos sin falta [...] al término de la misa jugaba con mis primos mientras mi mamá platicaba con mis tías (teníamos como siete años) [...] todavía recuerdo que si me portaba bien me compraba algo [...]" (Ramírez, G., Historia de vida, 05/01/2018). Lo anterior permite apreciar cómo el ser humano desarrolla apegos emocionales al vincular hechos o fragmentos de su vida con los elementos que han conformado su historia personal y colectiva.

La fractura identitaria se percibe desde diferentes sectores; uno de los más sobresalientes es la inexistencia de platillos típicos de la región. En consecuencia, los sanmiguelenses tienen preferencia por elementos característicos de otros estados del país, entre los que sobresalen Jalisco, Puebla y Oaxaca, los cuales impulsan un cambio cultural que replantea las formas de percibir y conocer los conocimientos locales, así como la reformulación de patrones y pautas de conducta. No obstante, San Miguel de Allende se ha caracterizado por ser una ciudad que oferta gastronomía nacional e internacional, pero no local; es común que mercados, cocinas económicas y restaurantes oferten tacos, enchiladas, pozole, tortas ahogadas, chiles rellenos, mole, y gorditas, que representan nichos geográficos de toda una nación. A pesar de que el destino carece de un platillo típico que lo represente gastronómicamente desde sus técnicas culinarias, productos de temporada, o preparaciones tradicionales, se identificó que el tumbagón, un dulce típico en forma de anillo que se elabora a base de harina de trigo, huevo, anís, azúcar glas, entre otros ingredientes, es un símbolo distintivo para la población, pues los sanmiguelenses consideran que si algún turista no lo prueba, es como si no hubiera visitado el lugar. 
Tabla 3

CLASIFICACIÓN DE SITIOS DE ACUERDO A IMPORTANCIA HISTÓRICA Y REPRESENTATIVIDAD TURÍSTICA

\begin{tabular}{|c|c|c|}
\hline Posición & $\begin{array}{l}\text { Importancia } \\
\text { histórica }\end{array}$ & $\begin{array}{l}\text { Representatividad } \\
\text { turística }\end{array}$ \\
\hline 1 & Museo casa de Allende & $\begin{array}{c}\text { Parroquia de } \\
\text { San Miguel Arcángel }\end{array}$ \\
\hline 2 & $\begin{array}{c}\text { Parroquia de } \\
\text { San Miguel Arcángel }\end{array}$ & $\begin{array}{c}\text { Santuario de Jesús } \\
\text { Nazareno de Atotonilco }\end{array}$ \\
\hline 3 & $\begin{array}{c}\text { Santuario de Jesús Nazareno } \\
\text { de Atotonilco }\end{array}$ & El Chorro \\
\hline 4 & $\begin{array}{c}\text { Centro de } \\
\text { San Miguel de Allende }\end{array}$ & El mirador \\
\hline 5 & Casa de cultura & Mercado de artesanías \\
\hline 6 & Bellas artes & $\begin{array}{l}\text { Jardín botánico } \\
\text { "Charco del Ingenio" }\end{array}$ \\
\hline 7 & Instituto Allende & Cañada de la virgen \\
\hline 8 & $\begin{array}{c}\text { Jardín botánico } \\
\text { "Charco del Ingenio" }\end{array}$ & Fabrica la Aurora \\
\hline 9 & Cañada de la virgen & $\begin{array}{c}\text { Centro de } \\
\text { San Miguel de Allende }\end{array}$ \\
\hline 10 & Los lavaderos & Bellas artes \\
\hline 11 & Palacio municipal & Museo casa de Allende \\
\hline 12 & Fabrica la Aurora & Los lavaderos \\
\hline 13 & Parque Benito Juárez & Parque Benito Juárez \\
\hline 14 & Teatro Ángela Peralta & ------------------ \\
\hline Sin ponderación & $\begin{array}{c}\text { El Chorro } \\
\text { El mirador } \\
\text { Mercado de artesanías }\end{array}$ & $\begin{array}{c}\text { Teatro Ángela Peralta } \\
\text { Palacio municipal } \\
\text { Instituto Allende } \\
\text { Casa de cultura }\end{array}$ \\
\hline
\end{tabular}

Fuente: elaboración propia con base en resultados del cuestionario. 
Otro de los habitantes refiere que: "San Miguel de Allende no tiene una cocina típica, pero existe una gran variedad de restaurantes de cocina de autor en la que mezclan elementos de la comida tradicional mexicana y la cocina internacional" (Cuestionario, 03/01/2018). Tal testimonio, además de los recorridos realizados en el destino, permiten argumentar que la comida internacional se ha convertido en un área de oportunidad para empresarios y comerciantes dadas las exigencias del turismo que arriba a la zona; por tanto, SMA se ha convertido en un destino cosmopolita donde es posible encontrar restaurantes de comida mexicana, china, japonesa, italiana, argentina, entre otras. Jóvenes sanmiguelenses admitieron que la pizza y las hamburguesas son parte de la dieta de los residentes, argumento que probaría que se han adherido nuevos hábitos y patrones alimentarios a causa de la globalización y de la actividad turística.

El lenguaje es otro elemento importante para la conformación de identidades. Para los sanmiguelenses el idioma español ha perdido terreno frente al inglés, al francés e incluso al italiano, puesto que aprender nuevos idiomas se ha vuelto una necesidad para comunicarse con los turistas; ante esta situación, refieren que han tenido que ceder a las exigencias del mercado, desarrollando nuevas habilidades que les permiten comunicar e interactuar con el visitante. Con la intención de profundizar sobre este hecho, se retoma un fragmento de la historia de vida de Gutiérrez, A.: "[...] soy comerciante, no tengo estudios porque mis papás no tenían pa' pagarlos, por eso empecé a trabajar desde chiquito [...] mis hijos ya van en secundaria, les dan clases de inglés, yo les digo que le echen ganas para que no sufran lo que yo sufrí, tuve que aprender de oído; en mis tiempos el inglés ni sonaba, pero ahora si no lo hablas no eres nadie, por lo menos aquí [...]" (29/12/2017).

A pesar de que éste se ha convertido en un idioma altamente demandado en el destino, es de resaltar que sus habitantes lo reconocen como un elemento cultural que los distingue de la otredad. Aseguran que su forma de hablar es única en comparación a la de turistas y visitantes, de tal forma que la jerga local, el tono y el ritmo de hablar son factores que les facilitan identificar a personas ajenas a la región; en palabras de Jiménez, D.: "Hablamos cantadito" (Entrevista, 02/11/2017). El lenguaje expresa para ellos una manifestación cultural que delimita tanto espacios geográficos como sociales. De manera complementaria los sujetos de estudio aseguran que los rasgos físicos de una persona, la forma de vestir, incluso el que lleve o no una cámara fotográfica, dista del "sanmiguelense tradicional".

En otro punto de ideas, las festividades populares y religiosas que tienen lugar a lo largo del año en SMA, permiten que turistas y visitantes se adentren a la cultura local mediante el consumo de referentes que conforman la identidad de los habitantes de SMA. Ante esta situación los sanmiguelenses participan de manera activa en actividades que refuerzan las tradiciones y costumbres que han pasado de generación en generación, las cuales en la actualidad son parte importante de la imagen turística que han construido en torno al destino y a sus manifestaciones culturales.

Asimismo, los pobladores tienen un vínculo estrecho con la religión católica, factor que ha impulsado la conmemoración de festejos con base en el calendario litúrgico. De las celebraciones religiosas ligadas a los santos que veneran en las distintas parroquias del municipio, figuran en orden de popularidad: San Miguel Arcángel, San Antonio de Padua, 
la Virgen de Guadalupe, la Santa Cruz, el Señor de la Columna, la Virgen de Loreto, San Francisco de Asís y la Virgen de la Salud, entre otros.

Sobre este aspecto, la parroquia principal representa un ícono social, cultural, religioso, arquitectónico y turístico para la región. La fiesta en honor a San Miguel Arcángel (29 de septiembre) es una de las más grandes y antiguas del municipio; se caracteriza por eventos culturales y artísticos que promueven la gastronomía, la venta de productos locales, espectáculos de pirotecnia, danzas, trajes típicos, música y rituales, entre otras actividades.

Anteriormente en esa fecha se realizaba la sanmiguelada (corrida de toros) que intentaba recrear la famosa pamplonada que tiene lugar año con año en Pamplona, España. Sin embargo, la población local se manifestó en su contra argumentando que promovía violencia, consumo excesivo de alcohol y de otras sustancias, además de proyectar una imagen negativa para el destino, además de generar inseguridad; por tanto, en 2007 se llevó a cabo por última vez. En una de las entrevistas se deja ver que la celebración no coincide con las tradiciones y creencias de la población, sino que se implantó por una familia de ascendencia española que se encontraba en el poder a principios de la década de los 70's.

Otra de las festividades que distinguen a SMA en el contexto nacional e internacional es el culto a la muerte ( 29 de octubre al 2 de noviembre). La celebración de los fieles difuntos integra un cúmulo de elementos simbólicos que dan sentido a la trascendencia del ser humano al término de la vida. En el jardín central son exhibidas ofrendas monumentales que muestran la creatividad de residentes, hoteleros, restauranteros, comerciantes y asociaciones, entre otros participantes. Bebidas, alimentos, fotografías, flores, veladoras, copal, artículos personales, son algunos de los elementos que dan sentido a esta representación del día de todos los santos. Es de resaltar que las tradicionales ofrendas permiten apreciar el sincretismo religioso entre creencias y/o representaciones de origen prehispánico y colonial.

A pesar de que el día de muertos es una tradición en todos los rincones de México, es justamente en SMA donde se ha gestado una integración social entre locales y foráneos. El testimonio de Castañeda, S. plantea: “A los extranjeros les gusta participar en estas fechas junto a nosotros [...] yo diría que el halloween no se ve por San Miguel de Allende [...] las personas de fuera son respetuosas con lo que representa para nosotros festejar a nuestros muertos y ellos se integran como uno más [...]" (Entrevista, 02/11/2017). No obstante, un desfile de catrines y catrinas se ha incorporado a las celebraciones de esta fecha conmemorativa; las autoridades locales refieren que: "el desfile fue creado en SMA sí, pero una mujer de origen estadounidense fue quién inició todo" (Entrevista, 04/11/2017).

En complemento a lo anterior, la población local refirió que otras de las celebraciones más representativas e importantes para SMA y su gente son: La Candelaria (febrero), Señor de la conquista (marzo), San José (marzo), Semana Santa, Señor de la columna (marzo), Valle del Maíz (mayo), San Antonio de Padua (fiesta de los locos, junio), Independencia de México (septiembre), La Alborada (septiembre) y Navidad (diciembre), donde cada una de ellas representa un elemento de aprovechamiento turístico para San Miguel de Allende y zonas aledañas al destino.

Si bien estos eventos son parte importante de la identidad sanmiguelense, es de reconocer que el destino ha incorporado nuevas celebraciones que difunden la grandeza artística 
y cultural; ejemplo de ello son festivales de distintas manifestaciones artísticas: música (Festival Internacional de Jazz \& Blues); cine (Guanajuato International Film Festival); teatro (Festival de Títeres San Miguel de Allende); gastronomía (Festival del cordero y el mezcal); literatura (Festival Internacional de Escritores y Literatura). En algunos se fusionan varias de estas categorías, como el Festival de Gastronomía, Enología y Música Electrónica "Born to be Wine".

Según testimonios del sector público y privado, la zona centro de SMA se ha posicionado como la "más adecuada" para la realización de actividades de alta afluencia porque posee infraestructura, servicios, espacio, recursos y otras características que no tienen las zonas aledañas para sacar adelante este tipo de eventos. En suma, según los turistas consultados, SMA es reconocido ampliamente como una ciudad amigable y receptiva con los visitantes de diferentes partes del mundo que viajan para conocer y experimentar las alternativas que oferta el destino; ello denota una íntima relación entre grupos endógenos y exógenos.

Por otra parte, según la población entrevistada, han tenido que aprender "sobre la marcha" la atención a los visitantes porque no todos tienen una formación profesional en el área turística, administrativa, gastronómica y hotelera; por tanto han debido capacitarse y certificarse para cubrir las demandas de un mercado que se transforma constantemente. Por esta razón ha sido necesario innovar en las formas de promocionar y vender productos y servicios, aunque respetando atributos históricos y culturales de SMA, al ser la que atrae al turista.

De manera paralela, turistas y visitantes observan desigualdad económica en el área que va del centro de la ciudad hacia la periferia, debido a la concentración de recursos en beneficio de los dueños de negocios cercanos a la zona perimetral. Al respecto, las autoridades afirman que quienes llegan a residir a SMA tienen un poder adquisitivo que les permite permanecer en un destino con gustos "exquisitos" y precios marcados por la demanda de carácter internacional.

Asimismo, las tradiciones y costumbres que perduran en el municipio exhiben el arraigo cultural de los sanmiguelenses. Sobre el particular, un funcionario público el área turística mencionó: "año con año las celebraciones en este lugar me han sorprendido gratamente; llevo viniendo ocho años consecutivos y siempre tengo ganas de regresar [...] siempre hacen cosas diferentes" (Giménez, H., entrevista 15/01/2018). A partir de ese testimonio se aprecia que el sector público, social y privado ha reinventado la manera de hacerle frente a exigencias del turismo nacional e internacional, consolidando el uso y reconocimiento de distintivos locales, para la difusión y comercialización de su imagen turística.

También se identificó que un reconocimiento social a partir del cual los visitantes posicionan a SMA como un espacio de talla internacional, es que artistas de diferentes partes del mundo arriban para incorporarse en alguna de las diferentes escuelas que imparten cursos sobre las bellas artes, convirtiéndose en una alternativa para la producción artística con esencia mexicana, así como una plataforma para darse a conocer dentro de un gremio selecto.

En cuanto a los turistas nacionales, éstos reconocen a SMA como una de las diez ciudades mexicanas patrimonio de la humanidad. Resalta el hecho de que ocho de ellas son capital de su respectivo estado de la República (Campeche, Ciudad de México, 
Guanajuato, Morelia, Oaxaca, Puebla, Querétaro y Zacatecas); dos de esas ciudades son municipios de entidades federativas (Tlacotalpan de Veracruz y San Miguel de Allende, de Guanajuato).

El hecho de que SMA sea reconocido internacionalmente por sus recursos patrimoniales, ha favorecido la inversión y con ello la creación de un polígono industrial que demanda fuerza laboral local para atender la producción de empresas nacionales y extranjeras. En este campo, la preservación de tradiciones y la conservación de los bienes inmuebles han beneficiado a los sanmiguelenses en materia laboral y además posibilitado a familias e individuos prestar sus servicios para atender la demanda turística.

Respecto a otro rubro del análisis, $85 \%$ de los sanmiguelenses entrevistados aseveró que el turismo ha potencializado la modificación de la identidad colectiva debido a que éste promueve la interacción social entre locales/nacionales y entre locales/extranjeros. En tal sentido, el intercambio de información, la incursión de población exógena y el acaparamiento territorial han diversificado las formas de concebir sus propias manifestaciones culturales a causa de la incorporación de elementos de culturas ajenas a la suya (tradiciones, costumbres, idioma, moneda local (de pesos a dólares), entre otros. Desde otra perspectiva, $13 \%$ confirmó que el turismo no tiene repercusión alguna sobre quiénes son y lo que hacen; al contrario, lo asocian con beneficios de enriquecimiento del bagaje intelectual, lingüístico, profesional, educativo, cultural e incluso económico.

En lo que corresponde a su faceta de modelo turístico, autoridades locales aseguran que SMA es una de las opciones más prósperas y completas tanto de México como del mundo. Su internacionalización es resultado de estrategias promocionales que han elevado la competitividad del sector, transformando el perfil de visitantes y residentes, pues se estima que éstos gozan de una estabilidad económica que les permite acceder a la amplia variedad de la oferta turística.

En resumen, la mitad de los testimonios de visitantes y turistas coincidieron en que la actividad turística ha promovido el rescate de la cultura sanmiguelense, ya que representa una fuente de ingresos "rentable" que beneficia a un pequeño grupo (sector privado), pero escasamente a la población local (sector social). Por su parte, el sector público está facultado mediante sus diferentes instancias para preservar y difundir el patrimonio local; sin embargo, es el sector social el que fomenta de primera mano la conservación y el respeto de los bienes culturales (materiales e inmateriales) entre miembros del colectivo sanmiguelense y los turistas que llegan a este destino. Aunado a esta cifra, $27 \%$ sostuvo que el turismo promueve de manera parcial el rescate de su cultura, afirmando que la cultura se conservará en la medida de que la población respete y sea fiel a sus orígenes; el 23\% restante asoció la preservación de formas culturales al interés de las personas por conocer más acerca del lugar donde vive y de la historia de su pasado.

Por su parte, una de las autoridades consultadas para el estudio, aseguró: "No vivimos solamente del recuerdo; continuamos trabajando día tras día, mes tras mes en la promoción de SMA [...]; no porque estemos ahorita en los cuernos de la luna lo vamos a estar siempre. Seguimos diversificando productos [...] participando en tianguis turísticos tanto nacionales como internacionales, en distintos foros, en distintos eventos sobre nichos de mercado de diversa gama [...] Colaboramos todos, tanto el sector público, privado 
para crecer de manera ordenada y alentar un turismo responsable" (Olalde, J., entrevista, 04/01/2018).

En cuanto a bienes intangibles, el sector público y privado asegura estar trabajando por conservar la identidad sanmiguelense, preservando tradiciones y costumbres representativas del destino, así como las prácticas de su gente. En cuestión de infraestructura y bienes inmuebles, la conservación masiva de la imagen de las casas (fachadas), las calles (empedrados y adoquín) y los sitios turísticos, han sido acondicionados para recibir al turismo; también señalética, nuevos accesos para personas con discapacidad y alumbrado público son solo algunos de los cambios efectuados.

Es de resaltar que en SMA existen bienes inmuebles que el Instituto Nacional de Antropología e Historia (INAH) resguarda por su valor histórico y cultural que los hace únicos y representativos de la región. Por tanto, ninguna persona puede realizar cambios o alteraciones sin permiso de esa dependencia pública.

La importancia que tuvo SMA durante la independencia de México (1810-1821) se ha convertido en un referente retomado para impulsar la actividad turística de la región. En este sentido, los hechos históricos han trascendido durante generaciones, afianzando el conocimiento local sobre el origen de la ciudad y de las prácticas sociales que en él se desarrollan (memoria colectiva). Aunado a esto, la riqueza y diversidad cultural que caracteriza al destino se ha posicionado en el gusto de visitantes y turistas de todo el mundo.

Ante esta situación, las manifestaciones culturales que van de lo tradicional a lo moderno han cobrado fuerza a causa de la demanda de un sector cada vez más exigente. La intervención del gobierno mediante su política turística, ha tenido que adecuar la manera de ofertar servicios, puesto que se han elevado los estándares para la satisfacción de necesidades primarias, secundarias y terciarias, promoviendo el consumo de experiencias "cinco estrellas" (hospedaje, restaurantes, spas, entretenimiento, etcétera).

De acuerdo con testimonios del sector hotelero, la forma de contribuir al desarrollo económico y turístico de SMA es ofertando diversas alternativas que se adapten a requerimientos de turistas y visitantes, así como brindar servicios de calidad que satisfagan las expectativas del cliente que los ha elegido de entre un cúmulo de opciones. Asimismo, los empresarios dieron a conocer que en México existe un impuesto sobre hospedaje que varía en cada entidad federativa y que para el caso guanajuatense es de $2 \%$ sobre el impuesto de la renta. Los recursos obtenidos se depositan a manera de impuestos, siendo una retribución que el huésped paga por el servicio.

Los montos anuales se distribuyen de manera proporcional entre la Secretaría de Finanzas, Inversión y Administración y la Secretaría de Turismo del Estado de Guanajuato. Estas instancias a su vez asignan recursos al municipio para infraestructura, servicios, mantenimiento, etcétera. En tal sentido, el sector privado asegura que la derrama económica ha favorecido la obtención de recursos por parte otros organismos. Por su parte, empresarios y representantes de la asociación de hoteles de SMA aseguran estar trabajando para que plataformas como Airbnb y Tripadvisor empiecen a pagar impuestos sobre el servicio de hospedaje, asegurando que deben retribuir de alguna forma a la población, a las autoridades y a las leyes del estado.

Finalmente, $46 \%$ de la población entrevistada asegura que el turismo los ha apoyado a reafirmar su identidad como sanmiguelenses, ante el rescate de los bienes que los repre- 
sentan local y globalmente; $42 \%$ testificó que la identidad se diversifica ante la fusión de elementos que no necesariamente son de carácter endógeno; es decir, existe una fusión entre referentes locales y foráneos; el $12 \%$ restante mencionó que la actividad turística inhibe o reprime la identidad local debido a que el modelo turístico está centrado en la satisfacción de necesidades de la comunidad extranjera, dejando de lado a los sanmiguelenses, lo cual contribuye a que no exista un empoderamiento de la identidad.

\section{CONCLUSIONES}

San Miguel de Allende ha permanecido vigente en el gusto de la comunidad nacional e internacional por diversas razones: sus recursos históricos, naturales y culturales; su abanico de productos y servicios, así como la hospitalidad de la gente. El modelo turístico que ha impulsado de manera conjunta el sector público, social y privado se ha adecuado a estándares internacionales que permiten experimentar el México tradicional con un toque de vanguardia, ejemplo de ello es la oferta hotelera y restaurantera de la ciudad. Ante esta situación se han rescatado elementos de la cultura local para difundir la riqueza de la región ante el contexto global, reafirmando el uso y representación de manifestaciones, así como la adopción de nuevas alternativas que promuevan el arte y la cultura en sus distintas representaciones (danza, música, cinematografía, literatura, escultura, pintura y arquitectura).

Los sanmiguelenses reconocen que el uso y preservación del patrimonio ha impulsado el crecimiento económico del destino y elevado el nivel de vida de su gente; sin embargo, la comunidad extranjera es quien más se beneficia del turismo, pues tiene suficientes recursos para invertir en mejoras (infraestructura, servicio al cliente, calidad en el producto, etc.) que les favorecen y en cambio representa un desventaja entre aquellos que carecen de recursos para competir en un mercado dinámico y cada vez más selecto. Ante esta situación, los grupos locales han encontrado en la cultura una alternativa rentable para distinguirse del resto, puesto que turistas y visitantes anhelan experimentar la esencia del destino.

Además, la actividad turística ha reparado el tejido social entre los sanmiguelenses, quienes trabajan de manera colaborativa para preservar la historia y la cultura que les han dado identidad durante décadas y que distinguen a SMA en todo el mundo. Ser un destino con reconocimiento internacional ha promovido la inversión pública y privada, canalizando recursos a la preservación de espacios y a fortalecer una imagen turística que favorece al centro del municipio dado que alberga el mayor número de atractivos; ante esto, residentes, avecindados y turistas se han beneficiado de la infraestructura y la concentración de servicios públicos y privados. Aunado a esto, la población local ha estrechado lazos con personas ajenas al contexto, siendo receptivos con los visitantes o con quienes deciden residir en él.

La principal razón que alienta la aceptación social de la comunidad de extranjeros en SMA se debe a las importantes contribuciones que ha realizado para el desarrollo académico, profesional y personal de la juventud sanmiguelense; ejemplo de ello son las donaciones de la biblioteca pública, las becas y/o apadrinamiento que reciben de la comunidad de extranjeros. De manera complementaria, la Agenda de Competitividad (2015) 
documenta que la comunidad extranjera que reside en este espacio cuenta con el respaldo de los sanmiguelenses; se han insertado en el tejido social, puesto que se les incorpora a la toma de decisiones sobre temas de interés para la población local.

Es anticientífico pensar que las identidades sean rígidas o estáticas; el ser humano forma parte de un colectivo que permea sobre la construcción del "yo", volviéndolo difícil de observar y definir dada la naturaleza del objeto de estudio. Aunado a esto, la construcción identitaria de los habitantes de San Miguel de Allende se nutre de su legado histórico, de su influencia religiosa y de la interacción con la otredad.

Éstos han incorporado y adaptado referentes identitarios de otros contextos geográficos y socioculturales a necesidades y/o preferencias individuales y colectivas; ejemplo de ello es el uso del inglés para comunicarse con extranjeros; el consumo de productos y la oferta de servicios apegados al perfil del consumidor; la resignificación de actividades lúdicas y populares, así como el reforzamiento de hábitos morales e intelectuales. Ante tal panorama, es posible apreciar que los habitantes de SMA poseen identidades flexibles que les permiten incorporar nuevas formas culturales. En otras palabras, su construcción identitaria ha conllevado un proceso durante el cual han adquirido formas culturales que favorecen el arraigo de la tradición y de la costumbre, al mismo tiempo en que incorpora referentes posmodernos a consecuencia de la actividad turística, entre ellos tecnología, medios de comunicación, actividades económicas y consumismo.

Por tanto, la identidad como proceso inacabado posee variaciones socioculturales que se adecuan a necesidades o exigencias individuales y colectivas. Ante el contexto global que permea en las sociedades del siglo XXI, es inevitable que las manifestaciones culturales muten o se transformen de acuerdo con el contexto donde se encuentren y a los factores que fracturan su estructura y función; es de reconocer que las identidades sanmiguelenses se han vuelto flexibles, ya que los procesos de socialización son cada vez más agresivos con la globalización y la actividad turística.

\section{REFERENCIAS BIBLIOHEMEROGRÁFICAS}

ANDRÉ, M. (2011): Tourism and identity. Disponible en http://www.academia.edu/download/16031351/Tourism_and_Identity.pdf

ANGROSINO, M. (2007): Etnografía y observación participante en investigación cualitativa. Madrid, Morata.

ARIAS, F. G. (2012): El Proyecto de Investigación. Introducción a la metodología científica (5ta ed.). Caracas, Episteme.

ARMENTA, G. (2014): ¿Cuál es la situación real de los 'Pueblos Mágicos'?. Forbes México. Disponible en https://www.forbes.com.mx/develan-misterios-de-los-pueblosmagicos/

BRENES LEIVA, R. (2006): "El Turismo en la Globalización”. CoRis: Revista de Ciencias Sociales y Humanidades, vol. 4 (1), pp. 21 - 30.

COHEN EMERIQUE, M. (1999): “Análisis de incidentes críticos: un modelo para la comunicación intercultural”. Revista Antipodes, vol. 145, pp. 465-480. 
DESTINOS MEXICO. (2018): Historia de San Miguel de Allende. Destinos México. Disponible en https://programadestinosmexico.com/descubre-mexico/historia/historiade-san-miguel-de-allende.html

FERNÁNDEZ, H.N. (2014): En busca de la identidad cultural como atractivo turístico (tesis de licenciatura). Universidad Abierta Interamericana, Argentina.

GIMÉNEZ, G. (2005): "Cultura, identidad y metropolitanismo global". Revista Mexicana de Sociología, vol. 67(3), pp. 483-512.

GIMÉNEZ, G. (2016): Estudios sobre la cultura y las identidades sociales. México, Secretaria de Cultura, Universidad Iberoamericana, ITESO, Universidad Veracruzana y Universidad de Guadalajara.

GIMÉNEZ, G. (2017): Argumento planteado en la cátedra "Debates teórico - metodológicos sobre la pareja conceptual cultura identidad". Universidad Nacional Autónoma de México (UNAM). México.

H. AYUNTAMIENTO GUANAJUATO (2016): San Miguel de Allende es declarado ganador en los premios "Condé Nast Traveler's Rreader Choice Awards 2016". H. Ayuntamiento Guanajuato. Disponible en http://sanmigueldeallende.gob.mx/?p=2735

HERRERA, A. (2018): El mural inconcluso de Siqueiros, tesoro en San Miguel de Allende. El Sol De México. Disponible en https://www.elsoldemexico.com.mx/republica/sociedad/el-mural-inconcluso-de-siqueiros-tesoro-en-san-miguel-de-allende-554981 html

LACA AROCENA, F. A., MEJÍA CEBALLOS, J. C y YAÑEZ VELASCO, C. (2010): "Identidad mexicana e interés político: Predictores de bienestar social y anomia". Acta Universitaria, vol. 20 (2), pp. 40-49.

LARRAÍN. J. (2001): Identidad chilena. Santiago, Lom Ediciones.

LEITE, N. y GRABURN N. (2009): Anthropological Interventions in Tourism Studies, en T. Jamal y M. Robinson (Ed.), The SAGE Handbook of Tourism Studies. London, SAGE, pp. 35-64.

LÓPEZ ESPINOZA, J. (2010): La Villa de San Miguel el Grande y Ciudad de San Miguel de Allende. México, SEGOB Guanajuato.

LÓPEZ SANTILLÁN, Á.A. y MARÍN GUARDADO, G. (2010): “Turismo, capitalismo y producción de lo exótico: una perspectiva crítica para el estudio de la mercantilización del espacio y la cultura. Relaciones". Estudios de historia y sociedad, vol. 31 (123), pp. 219-260.

MAC GREGOR, J. (2005): Identidad y Globalización en Patrimonio Cultural y Turismo. Cuadernos (No. 11): Primer Encuentro Nacional de Promotores y Gestores Culturales 2004. Memoria en cuatro actos. Distrito Federal, CONACULTA.

MELUCCI, A. (1985): Identità e azione colletiva, in: L. Balbo et alii, Complessità sociale e identità. Milán, Franco Angeli.

MILENIO DIGITAL. (2017): San Miguel de Allende "Mejor ciudad del mundo". Milenio Digital. Disponible en http://www.milenio.com/leon/san_miguel_de_allende-mejor_ ciudad_del_mundo-premio-milenio-noticias-leon_0_1000100458.html

MORAGUES CORTADA, D. (2006): Turismo, cultura y desarrollo. España: Organización de Estados Iberoamericanos para la Educación la Ciencia y la Cultura. Disponible en http://www.oei.es/historico/cultura/turismodmoragues.htm 
OCAMPO LÓPEZ, J. (2008): "Paulo Freire y la pedagogía del oprimido". Revista Historia de la Educación Latinoamericana, vol. 10, pp. 57-72.

ORTIZ URIBE, F. (2007): La entrevista de investigación en Ciencias Sociales. México, LIMUSA.

PIQUERAS INFANTE, A. (1996): La identidad valenciana: La difícil construcción de una identidad colectiva. Vol. 5. Madrid, Escuela Libre Editorial.

SABINO, C. (1992): El proceso de investigación. Caracas, Panapo.

SANDOVAL GODOY, S.A. (2003): "Hibridación social: un modelo conceptual para el análisis de la región y el territorio". Región y Sociedad, vol. 15 (28), pp. 47-80.

SECTUR GUANAJUATO. (2014): Agenda de competitividad de los destinos turísticos de México. México: SEGOB Guanajuato.

SECTUR GUANAJUATO. (2017a): Consejo turístico de San Miguel de Allende presenta informe de actividades. Secretaría de Turismo Guanajuato. Disponible en https://sectur.guanajuato.gob.mx/index.php/noticias/420-consejo-de-turismo-de-sma-presentainforme-de-actividades

SECTUR GUANAJUATO. (2017b): Presenta consejo turístico de San Miguel de Allende resultados turísticos de 2017. Secretaría de Turismo Guanajuato. Disponible en https:// sectur.guanajuato.gob.mx/index.php/noticias/893-presenta-consejo-de-turismo-desma-resultados-turisticos-de-2017

SECTUR. (2018): Sistema Nacional de Información Estadística y Geográfica de Turismo - SNIEGT. Secretaria de Turismo. Disponible en http://www.datatur.sectur.gob.mx/ CiudadesPatrimonio/SanMiguelDeAllende.aspx

SEGOB y SECTUR GUANAJUATO. (2017): Perfil del visitante San Miguel de Allende 2017. Secretaría de Gobernación y Secretaría de Turismo Guanajuato. Disponible en https://www.observatorioturistico.org/cenDoc/e61f0-Perfil-SMA-2017_OT.pdf

SEGOB y SECTUR GUANAJUATO. (2018): Descarga el mapa turístico de San Miguel de Allende. Guanajuato, México. San Miguel de Allende. El corazón de México. Disponible en http://visitsanmiguel.travel/

UNESCO. (2008): Protective town of San Miguel and the Sanctuary of Jesús Nazareno de Atotonilco.

UNESCO. Disponible en http://whc.unesco.org/en/list/1274

ZÚÑIGA BRAVO, F.G. (2013): "Los nuevos usos de la cultura y el patrimonio cultural en el contexto turístico de México. El caso del Totonacapan veracruzano", en C. Ochmichen Bazán (Comp.), Enfoques antropológicos sobre el turismo contemporáneo. México, UNAM, pp. 193-242. 